\title{
METODOLOGIA UTILIZADA PARA A EXTRAÇÃO DE GRÃOS DE PÓLEN DE COPRÓLITOS HUMANOS - UM ESTUDO COMPARATIVO
}

Os seis coprólitos humanos aqui estudados, datados de 8500 a 7000 anos AP, foram coletados no abrigo sob rocha da Toca do Boqueirão da Pedra Furada (8 51'10" S, 42 33'20" W) - Piauí, Brasil - que é considerado, nos dias de hoje, um dos mais antigos sítios pré-históricos da América. Esses coprólitos foram tratados por dois métodos distintos, a fim de estabelecermos uma comparação na quantidade final de taxons polínicos encontrados em cada uma das metodologias utilizadas.

A primeira metodologia consistiu das seguintes etapas: depois de pesados, fotografados, medidos e feita uma ficha individual para cada coprólito, foram separadas $2 \mathrm{~g}$ de cada amostra de coprólito (peso seco) e, a seguir, peneiradas em telas de cobre de malha de $200 \mu \mathrm{m}$. Esta última etapa tem por finalidade separar os sedimentos grosseiros ocasionalmente encontrados. O material então selecionado foi tratado da maneira que descrevemos a seguir:

- amostras argilo/arenosas - necessitaram do uso de $15 \mathrm{ml}$ de ácido fluorídrico, (HF) a frio, durante uma noite. Após essa etapa, optamos pelo tratamento convencional das amostras no "banho-maria", durante 10 a 15 minutos com ácido clorídrico ( $\mathrm{HCI}$ ) a $50 \%$. Após sucessivas centrifugações de 5 minutos a 3000 rpm e lavagens em água destilada, a solução final deve ficar clara.

- amostras ricas em matérias orgânicas Após o tratamento com o ácido clorídrico (HCI) acima descrito, escolhemos o método de Von Post, ou seja, optamos pela utilização de $15 \mathrm{ml}$ de Hidróxido de potássio, $(\mathrm{KOH})$ a $10 \%$, para dissolver os compostos orgânicos e eliminá-los com sucessivas centrifugações.

Após fervuras em "banho-maria" dos sedimentos deixados no $\mathrm{KOH}$ a $10 \%$, seguidas de centrifugações e lavagens sucessivas, sempre durante $3000 \mathrm{rpm}$ durante 5 minutos, obtivemos uma solução clara. Passamos então à etapa seguinte, que consiste no método químico clássico, ou seja, na utilização de um processo de extração, através de um líquido denso, Cloreto de $\mathrm{Zinco}\left(\mathrm{ZnCl}_{2}\right)$, que permite a separação dos pólens e esporos do restante da solução.

Após a separação da parte orgânica dos sedimentos, através do Cloreto de Zinco, uma nova etapa de centrifugações se segue, desta vez com a adição de $20 \mathrm{ml}$ de ácido clorídrico (HCL a 25\%), para reavivar a densidade.

Finalizando as centrifugações, que nesta etapa são de 1000 rpm durante 5 minutos, seguiramse lavagens com água destilada e preparou-se o material para a montagem final, deixando-o meia hora em uma solução de $20 \mathrm{ml}$ de água com glicerina a $10 \%$, o que facilitará a observação, em microscopia ótica, dos pólens encontrados.

Feito isso, foram preparadas as lâminas para contagem e identificação dos pólens e esporos, colocando-se em cada lâmina, $50 \mathrm{ml}$ de sedimento, com o auxílio de uma micro pipeta. A seguir, realizou-se a montagem propriamente dita, entre lâmina e lamínula, vedando as bordas da lamínula com "Histolaque" LMR.

Utilizamos, na segunda metodologia, uma técnica distinta, tanto na preparação química, como na montagem final das lâminas. A segunda metodologia constituiu-se então das seguintes etapas:

- pesagem de $2 \mathrm{~g}$ de material seco (coprólitos);

- trituração do material;

- tratamento com KOH A 10\%;

- utilização de ultra-som sobre o sedimento tratado;

- separação do material orgânico do inorgânico com $\mathrm{Zn} \mathrm{Cl}$;

- montagem das lâminas, segundo o método de Kisser (gelatina glicerinada).

Dos seis coprólitos tratados com este método, dois apresentaram uma quantidade razoável de taxons botânicos e os outros quatro apresentaram uma quantidade abaixo do necessário para uma contagem representativa (mínimo de 20 taxons e 150 pólens, em média, por lâmina). 
Aplicando a primeira metodologia, encontramos uma quantidade superior significativa de taxons. $\mathbf{O}$ quadro a seguir apresenta o resultado das duas metodologias utilizadas. Nele verificamos que duas das amostras-teste não apresentaram resultados positivos em nenhuma das duas metodologias utilizadas.

\begin{tabular}{|c|c|c|c|}
\hline Primeira & Metodologia & Segunda & Metodologia \\
\hline Coprólitos & (taxons) & & (taxons) \\
\hline 1 & 21 & & 7 \\
\hline 2 & 18 & & 2 \\
\hline 3 & sem pólen & & sem pólen \\
\hline 4 & sem pólen & & sem pólen \\
\hline 5 & 22 & & 4 \\
\hline 6 & 21 & & 14 \\
\hline
\end{tabular}

Ao final deste trabalho, acreditamos ter podido contribuir para uma melhora metodológica, no que diz respeito aos tratamentos químicos a serem utilizados na extração de pólens e esporos de coprólitos humanos.

\section{Agradecimentos}

Ao Dr. Adauto Araújo e ao Dr. Fábio Parenti por seus conselhos científicos. Ao CNPq - Conselho Nacional de Desenvolvimento Científico e Tecnológico - que deu o apoio financeiro para a elaboração deste trabalho.

\section{Sérgio Augusto de Miranda Chaves*}

\section{Referências bibliográficas}

ARAUJO, A.; FERREIRA, L. F.; CONFALONIERI, U.; CHAME, $M$.

1988 Hookworms and the peopling of America. $\mathrm{Ca}$ dernos de Saúde Pública. Rio de Janeiro, 2 (4): 226-233.

CHAME,M.;FERREIRA,L. F; ARAUJO, A.;CONFALONIERI, U.

1989 Testing the color parameter of coprolithes rehydration solution. Paleopathology Newsletter, 68: 9-11.

CHAVES, S. A. M.

1995 Etude palynologique des coprolithes humains recueillis sur le site "Pedra Furada" - Piauí
(Brésil); Interpretations paléoethnologiques et paléobotaniques. Mémoire de D.E.A - Quaternaire: Géologie, Paléontologie Humaine et Préhistoire - Muséum National D'Histoitre Naturelle, Paris, 60 p.

CHAVES, S. A. M.; RENAULT-MISKOVSKY, J.

prelo Paléoethnogie, paléoenvironnement et paléoclimatologie au Piauí, Brésil: apport de l'étude pollinique de coprolithes humains recueillis dans le gisement préhistorique Pléistocène de "Pedra Furada".

RENAULT-MISKOVSKY, J.; PETZOLD, $M$.

1992 Spores et Pollen. Editions Delachaux et Niestlé, Paris, 356 p.

Recebido para publicação em 10 de dezembro de 1995.

(*) Muséum National d'Histoire Naturelle, Institut de Paléontologie Humaine - Laboratoire de Palynologie. Paris, França. 